\title{
Participação Comunitária em Projetos de Desenvolvimento: um olhar sobre a execução do Prosanear I em Fortaleza-CE
}

\section{Community Participation in Development Projects: a look at the implementation of Prosanear I in Fortaleza-CE}

Luciana de Oliveira Dias - Doutora em Ciências Sociais (UnB). Professora da Educação Intercultural e do Programa de Mestrado em Direitos Humanos da Universidade Federal de Goiás - UFG. E-mail: lucianadeoliveira99@hotmail.com

Andrea Freire de Lucena - Doutora em Relações Internacionais (UnB). Professora da graduação em Ciências Econômicas e do Programa de Mestrado em Ciência Política da Universidade Federal de Goiás - UFG. E-mail: andflucena@gmail.com

\section{Resumo}

Estimativas do Relatório do Banco Mundial indicam que em 2025, dois terços dos habitantes da Terra viverão nas cidades. Para suportar esse aumento no número de residentes urbanos, as cidades devem investir substancialmente em saneamento básico. Todavia, importantes agentes na promoção de saneamento, tais quais governos e organismos internacionais, não raras vezes, elaboram e executam projetos que não consideram as realidades locais, exigindo das comunidades comportamentos exógenos a um ethos local. O Prosanear, surgido da necessidade de atendimento à população de baixa renda das cidades com serviços de saneamento, foi implantado em parceria com o Banco Mundial em diversas partes do Brasil e tem como peculiaridade o envolvimento da comunidade na busca por soluções dos problemas enfrentados. O objetivo deste artigo é verificar a aplicação do Prosanear I nos Conjuntos Palmeiras e São Bernardo, em Fortaleza-CE, na década de 1990, destacando elementos da participação comunitária. A coleta de dados foi realizada primeiramente no Conjunto Palmeiras (onde o projeto já tinha sido executado) e estes foram comparados com os dados coletados no Conjunto São Bernardo (onde o projeto estava ainda em execução). Os surveys aplicados nas comunidades e as entrevistas em profundidade permitiram compreender, dentre outras questões, em que medida as dificuldades destacadas pela comunidade no Conjunto Palmeiras foram consideradas pelo Banco Mundial durante a execução do projeto no Conjunto São Bernardo.

\section{Palavras-chave}

Participação comunitária. Projetos de desenvolvimento. Prosanear I

\begin{abstract}
The World Bank indicates that, in 2025, two-thirds of Earth's inhabitants will live in cities. To support this increase in the number of urban residents, cities must invest heavily in basic sanitation. However, governments and international organizations, often, develop and execute projects that do not consider local realities and communities. The Prosanear arose from the need to provide sanitation services to low-income people who live in cities. The program was implemented in partnership with the World Bank in various parts of Brazil and has the peculiarity of involving the community. The purpose of this article is to verify the implementation of Prosanear I in two districts of Fortaleza-CE called Conjunto Palmeiras and Conjunto São Bernardo, in the 1990s, highlighting aspects of community participation. Data collection was first made in Conjunto Palmeiras (where the project had already been executed) and these were compared with the data collected in Conjunto São Bernardo (where the project was still running). The surveys applied in communities and in-depth interviews allowed us to understand, among other issues, if the difficulties highlighted by the community at Conjunto Palmeiras were considered by the World Bank during project implementation at Conjunto São Bernardo.
\end{abstract}

\section{Keywords}

Community participation. World Bank. Prosanear I 


\section{INTRODUÇÃO}

Ações governamentais têm sido amplamente discutidas por várias correntes do pensamento econômico e social em que são pautadas estratégias para aumentar a eficiência e a eficácia das políticas públicas. Neste contexto, questionamentos tendem a remontar a diminuição da capacidade do Welfare State de ofertar políticas públicas capazes de suprir demandas crescentes. As ideias keynesianas, tão em moda nos anos de 1950, mas já aplicadas na década de 1930, postulavam que os mercados são sujeitos a falhas e, portanto, o governo deveria corrigir tais distorções do mercado. A década de 1980, todavia, assiste a outra inflexão, na qual o mercado se restabelece e passa-se a discutir as falhas do governo.

As correntes associadas a uma dimensão mais política e social ao entrarem no debate sobre uma crise do Welfare State permitem enfatizar, no âmbito da cidadania individual, a participação política e civil na sociedade nacional. De acordo com Pierre Rosanvallon (1995), a participação política e civil implica responsabilidades e deveres concretos. No que se refere à participação, o Banco Mundial (1995) informa que este fenômeno pode ser descrito como o fato de os atores sociais influenciarem e partilharem o controle sobre as decisões tomadas.

O Relatório sobre o Desenvolvimento Mundial 1999-2000 mostra quatro lições que devem ser cumpridas pelos países que almejam desenvolver-se: a) crescimento econômico acompanhado de acesso à educação, ao equilíbrio ambiental e à melhor distribuição de renda; b) interdependência das políticas de desenvolvimento; c) papel essencial do governo; d) processos e políticas têm a mesma importância. Neste último caso necessita-se de instituições consolidadas que defendam a participação, incorporem novos parceiros da sociedade civil, e fortaleçam os laços do setor público com o privado (SOTERO, 1999).

As várias políticas e programas dos governos e dos organismos internacionais para melhorar as condições de vida da população mais pobre do planeta não têm sido tão eficazes. Em 2025, dois terços dos habitantes da terra viverão nas cidades. Para suportar esse aumento no número de residentes urbanos, as cidades devem fazer grandes investimentos em saneamento básico. Todavia, governo e organismos internacionais elaboram e executam projetos que nem sempre levam em consideração as realidades locais e exigem comportamentos que as comunidades não possuem. O projeto chega pronto na comunidade, cabendo aos executores o papel de convencer a população da sua importância.

O Programa de Abastecimento de Água e Saneamento para População de Baixa Renda da Zona Urbana - Prosanear I foi implantado pelo Banco Mundial 
em diversas partes do Brasil. Sua característica peculiar é o fato de precisar da participação da comunidade, pois, para funcionar, todos precisam agir de forma harmônica. O objetivo desse artigo é analisar como se deu a participação comunitária na execução do Prosanear I nos Conjuntos Palmeiras e São Bernardo, localizados em Fortaleza-CE.

Para viabilizar a investigação foram comparados dados coletados inicialmente no Conjunto Palmeiras (local onde o projeto já tinha sido executado) com os dados do Conjunto São Bernardo (local onde o projeto estava ainda sendo executado). Ainda com relação à metodologia adotada, a produção de dados combinou duas técnicas: 1) Foi realizado um survey nas duas comunidades da periferia de Fortaleza; 2) Os procedimentos qualitativos foram assegurados mediante a realização de grupos focais (Grupo focal no Conjunto Palmeiras - GP; Grupo focal no Conjunto São Bernardo - GB) com membros dessas comunidades. As discussões e problematizações gravitam em torno da seguinte questão: as dificuldades apontadas pela comunidade no Conjunto Palmeiras foram levadas em consideração pelo Banco Mundial durante a execução do projeto no Conjunto São Bernardo?

\section{O BANCO MUNDIAL, O PROSANEAR I E A PARTICIPAÇÃO COMUNITÁRIA}

Depois da Segunda Guerra Mundial, os representantes de aproximadamente 50 países se encontraram em uma pequena cidade do Estado de New Hampshire (EUA) para tentar restaurar o sistema financeiro e monetário internacional. As negociações foram dominadas por duas grandes potências: o Reino Unido, que estava em declínio; e os Estados Unidos, que estavam em plena ascensão. Como afirma Clairmont (1994), o que estava em jogo era a nova configuração do poder econômico mundial.

A criação do BIRD (Banco Internacional de Reconstrução e Desenvolvimento) destinava-se a servir tanto à finalidade de reconstrução como à de desenvolvimento. Os países europeus lutavam para enfatizar a função de reconstruir. Enquanto os países menos desenvolvidos temiam que, se fosse dada muita ênfase à reconstrução, o Banco Mundial nunca se preocuparia com o desenvolvimento (MASON; ASHER, 1973).

A Guerra Fria entre EUA e União Soviética e a presença de instituições multilaterais (como o Banco Mundial) mudaram a feição da política mundial. Pequenos países passaram a ter lugar e garantia de voto tanto no âmbito da 
Assembleia Geral da ONU como em outros organismos internacionais. A descolonização ocorrida nos anos 1960, sobremaneira nos países africanos, fez crescer o número dos membros nos fóruns globais. Os países desenvolvidos deixaram de ser majoritários e isso permitiu que os países em desenvolvimento pudessem levantar questões anteriormente relegadas, especialmente as de ordem econômica e social. Assim, formou-se a chamada agenda do desenvolvimento, cuja base era a transferência de recursos dos países desenvolvidos para os em desenvolvimento (LIMA, 1996).

Nessa nova agenda desenvolvimentista, o Banco Mundial desempenharia um papel essencial. Inicialmente, ele começou com um compromisso perante uma nova ordem econômica pós-guerra. Seguindo a lógica de formação da agenda do desenvolvimento, apenas na década de 1960 é que o Banco Mundial decidiu direcionar-se para os membros menos favorecidos. De 1962 a 1967, o Banco Mundial tentou manter seu papel indispensável no desenvolvimento internacional expandindo sua capacidade de investimento (LESLIE, 1987). Aquele período foi caracterizado pela presença da ideia de crescimento com a intenção de desenvolvimento. Assim, defendiam-se e realizavam investimentos em áreas como infraestrutura.

Nos anos 1970, houve uma mudança substantiva na concepção de desenvolvimento, tendo aumentado a preocupação com a desigualdade. Vários países conseguiram implantar seus parques industriais e formar um setor privado organizado, contudo o crescimento econômico por si só, como se pensava anteriormente, não assegurava o desenvolvimento. Essa nova forma de ver a problemática dos países em desenvolvimento ficou explícita na presidência de MacNamara, segundo o qual, o desenvolvimento não significava apenas progresso via aumento do produto nacional bruto, mas também satisfação de necessidades básicas (LESLIE, 1987).

No entanto, grande parte dessas mudanças foi apenas aparente, pois o Banco Mundial continuou aprovando projetos e dedicando a maior parte do seu montante de investimento a setores como energia, transporte e telecomunicações. Ademais, o Banco Mundial deu sequência às soluções conservadoras para resolver os problemas de desenvolvimento do chamado Terceiro Mundo, tais quais: a abertura do mercado; e a necessidade de dispor de capital excedente por meio do crescimento da poupança interna.

Com a crise da dívida externa dos anos 1980, a linha divisória entre o Banco Mundial e o Fundo Monetário Internacional (FMI) foi ficando cada vez mais tênue. O Banco Mundial ampliou seu programa de empréstimo para minimizar o déficit na balança de pagamentos e a consequente deterioração dos termos de 
troca dos países em desenvolvimento. As diretrizes do Banco para os anos 1990 se distinguiram das propostas para a década de 1980. Todavia, a necessidade de equilíbrio orçamentário e de políticas macroeconômicas austeras permaneceu. Houve uma continuidade de estratégias, mas nos anos 1990, enfatizou-se a necessidade de um retorno social mais prático.

No início da década de 1990, o Banco Mundial elaborou um documento chamado Urban Policy and Economic Development: an Agenda for the 1990s no qual defendia a melhoria do acesso à infraestrutura básica com prioridade para as necessidades dos pobres. Além do mais, passou a reconhecer a importância da participação das organizações comunitárias e não-governamentais na oferta de bens e serviços de infraestrutura básica (SMOLKA, 1995). No campo do saneamento básico, passou a defender o uso de tecnologias alternativas de baixo custo (least cost alternative).

O Prosanear foi criado no final dos anos 1980 para fomentar o saneamento de áreas urbanas periféricas que não possuíam adequadas estruturas sanitárias. O programa associou definições de saneamento, de saúde e de meio ambiente, com o objetivo de aperfeiçoar as condições de vida das camadas sociais mais pobres (SANTOS; PAULA, 1989). O Prosanear I incorporou pressupostos fundamentais: participação comunitária, tecnologias apropriadas de baixo custo, proteção ambiental e recuperação de custos.

A participação comunitária significa que todo e qualquer projeto deve procurar adequar-se à realidade de cada comunidade. A participação, conforme o Banco Mundial, seria indispensável para o alcance dos objetivos previstos no projeto, pois a tecnologia de baixo custo selecionada e o sistema condominial exigiam uma integração entre vizinhos. Assim, a instalação das redes no quintal das residências obrigaria os moradores a colaborarem na manutenção do sistema. Além disso, o Banco Mundial sustentava que não adiantaria implementar soluções técnicas sem o apoio comunitário, pois a falta de participação inviabilizaria a execução do projeto.

Segundo o Banco Mundial, a implantação de sistemas não convencionais necessitaria da participação da comunidade em todas as fases - desde a elaboração do sistema, passando pela operação, até chegar à etapa da manutenção. Dessa forma, para o Banco Mundial, as comunidades participariam do processo de tomada de decisões em todas as fases dos projetos (SANTOS; PAULA, 1989). Assim sendo, a participação passa a estar associada com melhores resultados dos investimentos.

A tecnologia apropriada de baixo custo mais utilizada foi o sistema condominial, cuja nomenclatura advém do fato desse sistema de esgoto ligar um 
grupo de domicílios como em um edifício horizontal. Neste caso, o esgoto passa perto ou dentro de cada terreno. Assim sendo, os moradores que participam do planejamento, construção e manutenção do sistema, têm a oportunidade de escolher uma das três alternativas: fundo de lote, em que as redes do quarteirão passam no quintal do morador, atravessando todo o quarteirão e saindo numa linha da rua; frente do lote, em que as redes se localizam na frente da residência e uma tubulação é colocada em cada lado do quarteirão; e na calçada, onde a rede é posta embaixo da calçada na frente do domicílio. Depois da escolha da opção tecnológica pelos moradores, cada domicílio assinava um termo de adesão e se comprometia a pagar pelo serviço e a manter o sistema em funcionamento (SANTOS; PAULA, 1989).

O Prosanear I tinha também compromisso com a proteção ambiental, por isso o financiamento a projetos de abastecimento de água deveria estar conjugado com o tratamento adequado dos esgotos. O pressuposto era o de que não adiantaria fornecer apenas água às comunidades, pois elas iriam jogar as águas servidas nas ruas, prejudicando o meio ambiente e incitando o aparecimento de doenças. Além do fornecimento de água era necessário dar um destino adequado ao esgotamento sanitário (SANTOS; PAULA, 1989).

Por fim, o Prosanear I cobraria dos usuários as ligações domiciliares, o uso da água e a coleta do esgoto. O pagamento, conforme defendia o Banco Mundial, compromete os beneficiários com o serviço, pois se fosse gratuito o sistema seria rapidamente depauperado. Nesse caso, o fato de o usuário pagar o obrigaria para com a manutenção dos equipamentos.

\section{CARACTERIZAÇÃO DOS CONJUNTOS PALMEIRAS E SÃO BERNARDO}

O Conjunto Palmeiras fica localizado a sudoeste da zona urbana de Fortaleza, a $22 \mathrm{~km}$ do centro da cidade, no bairro Jangurussu e foi criado em 1973 com a transferência, realizada pela Prefeitura, dos desabrigados das enchentes e de famílias desapropriadas de áreas de ocupação urbana. $\mathrm{Na}$ época da realização dos surveys e das entrevistas existiam 5.250 lotes cadastrados na Prefeitura, sendo que a população estimada era de 26.250 habitantes. A maioria dos moradores era casada (64,0\%), e com mais de 31 anos de idade (70,0\%). Quase 2/3 dos residentes $(65,0 \%)$ viviam no local há mais de nove anos. A população possuía baixa escolarização: quase $1 / 5$ dos adultos eram analfabetos $(19,0 \%)$ e $37,5 \%$ tinham entre a $1^{\mathrm{a}}$ e a $4^{\mathrm{a}}$ série do ensino fundamental. Os que estudaram da $5^{\mathrm{a}}$ à 
$8^{a}$ série era pouco mais de $1 / 4$ (26,5\%). Cerca de 17,0\% tinham entre o ensino fundamental e o ensino médio completos.

O Conjunto São Bernardo, localizado no bairro Cambeba dentro do distrito de Messejana e situado ao sul da zona urbana de Fortaleza, foi loteado pela Companhia de Habitação $(\mathrm{COHAB})$ em regime de mutirão. Sua formação se deu em 1990 com a transferência dos moradores da zona de ocupação São Miguel para a área. A sua população estimada era, de 3.105 habitantes, sendo que $80,0 \%$ da população moravam lá há mais de seis anos. Mais da metade $(58,5 \%)$ possuía entre 28 e 47 anos de idade e 82,5\% eram casados. Quanto à escolaridade, mais de $2 / 3(69,5 \%)$ dos moradores fizeram entre $1^{\text {a }}$ e a $8^{\mathrm{a}}$ série, e apenas $8,5 \%$ terminaram o ensino fundamental e $17,5 \%$ são analfabetos. A escolarização dos moradores do São Bernardo era inferior à observada entre os residentes do Palmeiras, concentrando-se entre a $1^{\mathrm{a}}$ e a $4^{\mathrm{a}}$ séries do ensino fundamental. A tabela abaixo auxilia na visualização comparativa entre as duas localidades à época da pesquisa (Tabela 1).

Tabela 1. Escolaridade dos moradores (\%)

\begin{tabular}{l|c|c}
\hline \multicolumn{1}{c|}{ Escolaridade } & $\begin{array}{c}\text { Conjunto } \\
\text { Palmeiras }\end{array}$ & Conjunto São Bernardo \\
\hline Analfabeto & 18,9 & 17,4 \\
\hline Entre $1^{2}$ e $4^{2}$ série & 37,4 & 50,0 \\
\hline Entre 5 e 8 série & 26,5 & 19,6 \\
\hline Ensino Fundamental completo & 8,9 & 8,7 \\
\hline Ensino Médio incompleto & 4,8 & 4,3 \\
\hline Ensino Médio completo & 3,2 & - \\
\hline Acima do Ensino Médio completo & 0,3 & - \\
\hline Total & 100,0 & 100,0 \\
\hline
\end{tabular}

Fonte: Elaboração própria.

A baixa escolaridade parece refletir no perfil ocupacional dos moradores do Conjunto Palmeiras: 43,0\% exerciam atividades não qualificadas ou de baixa qualificação e apenas 14,5\% desempenhavam funções qualificadas, manuais ou não. Em ambos os casos, estavam agregadas as ocupações manuais e as não manuais. Pode-se mencionar que a baixa escolaridade também se refletia na ocupação dos moradores do Conjunto São Bernardo, pois 37,0\% desempenhavam atividades não qualificadas ou de baixa qualificação. Por outro lado, apenas 8,5\% exerciam alguma função qualificada, contra 14,5\% constatados no Conjunto Palmeiras. Vejamos a demonstração na tabela abaixo: 
Tabela 2. Ocupação ${ }^{1}$ dos moradores (\%)

\begin{tabular}{|l|c|c|}
\hline \multicolumn{1}{|c|}{ Ocupação } & Conjunto Palmeiras & Conjunto São Bernardo \\
\hline Manual não Qualificada & 19,8 & 4,3 \\
\hline Manual de Baixa Qualificação & 15,0 & 26,1 \\
\hline Manual Qualificada & 7,0 & 6,5 \\
\hline Não manual de Baixa Qualificação & 8,3 & 6,5 \\
\hline Não manual Qualificada & 7,3 & 2,2 \\
\hline Donas de Casa e Estudantes & 33,3 & 54,4 \\
\hline Aposentados e Pensionistas & 9,3 & - \\
\hline Total & 100,0 & 100,0 \\
\hline
\end{tabular}

Fonte: Elaboração própria.

A comunidade do Conjunto Palmeiras contava com vias pavimentadas e $2 / 3$ dos entrevistados informaram que a rua onde moravam era calçada e $22,0 \%$ informaram que a rua era asfaltada. Contudo, 11,0\% relataram que a via urbana ainda era de terra. Em 98,0\% dos casos a moradia era própria e, em 100,0\% o domicílio era do tipo casa construída em alvenaria, sendo que 95,0\% delas tinham cobertura de telhas e $69 \%$ tinham pisos de cimento bruto ou cimento queimado. $11,5 \%$ dessas casas tinham entre 1 a 3 cômodos, e 70,5\%, tinham de 4 a 7 cômodos. $40,5 \%$ das residências eram habitadas por até quatro pessoas, contudo 53,5\% dos domicílios tinham entre 5 a 9 pessoas. Quase todas as casas contavam com energia elétrica regular $(99,0 \%)$ e 35,5\% não usam água filtrada.

As ruas de $91,5 \%$ dos domicílios do Conjunto São Bernardo eram calçadas e $100 \%$ das residências eram próprias. Um pouco mais da metade $(54,5 \%)$ dessas casas eram pequenas, contando entre 3 a 5 cômodos, o restante tinha dimensões um pouco maiores, com 6 a 8 cômodos. Eram residências habitadas por até nove pessoas, sendo que 41,5\% tinham de 2 a 4 moradores e 46,0\% de 5 a 7 . Todas as casas eram de alvenaria e cobertas de telha, mas 76,0\% tinham como piso cimento ou cimento queimado. $93,5 \%$ possuíam energia elétrica com ligação regular e $69,5 \%$ possuíam filtro.

O exame dos hábitos e condutas relativos às práticas sanitárias e ambientais dos moradores no Conjunto Palmeiras mostrou um cenário bastante favorável.

1 Ocupações manuais qualificadas: auxiliar de carga, auxiliar de castanha, entregador, gari, lavadeira, empregada doméstica, ajudante de construção, serviços gerais, servente, cobrador de ônibus, ajudante de caminhão, agricultor, catador de lixo, merendeira, serralheiro, vidraceiro, marceneiro, pintor, pedreiro, motorista, carreteiro, moto-taxista; Ocupações manuais de baixa qualificação: manicure, sapateiro, cabeleireira, jardineiro, cozinheiro, artesão, pescador, costureira de todos os tipos, cortador de confecção, doceira; Ocupações não manuais de baixa qualificação: auxiliar de escritório, atendente, agente administrativo, vendedores de todos os tipos, vendedor de churrasquinho, vigia, vigilantes de todos os tipos, zelador de todo tipo, porteiro; Ocupações não manuais qualificadas: professores de todos os tipos, contabilista, comerciante, escrevente de cartório, tenentes.

Novos Cadernos NAEA • v. 16 n. 2 • p. 319-339 • dez. 2013 
Uma elevada parcela da comunidade $(93,0 \%)$ armazenava o lixo em caixas e sacos e 95,5\% usavam a coleta pública como destino final do lixo. Apenas 4,0\% ainda se aproveitavam dos terrenos baldios e vias públicas para depositar entulhos.

85,0\% dos habitantes do Conjunto São Bernardo armazenavam o lixo em sacos e $95,5 \%$ utilizavam a coleta pública como destino final para ele. Com relação aos hábitos de higiene pessoal, todos afirmaram tomar banho todo dia, 91,5\% disseram que lavam as mãos antes das refeições e 98,0\% costumam escovar os dentes diariamente. A maioria, 78,5\%, enfatizou que usualmente ferve ou filtra a água de beber. 52,0\% responderam que não cobrem os depósitos de água. 58,5\% dos moradores combatiam ratos, moscas e baratas, entretanto, 41,5\% não faziam a mesma coisa. Entre os instrumentos de combate, o veneno foi citado por $50 \%$ dos entrevistados.

Com relação aos hábitos de higiene pessoal da população do Conjunto Palmeiras, 98,5\% afirmaram que tomam banho todo dia e 97,0\% disseram que lavam as mãos antes das refeições e que escovam os dentes diariamente. Somente $67,0 \%$ costumavam ferver ou filtrar a água de beber e 69,5\% não cobriam as caixas ou outros depósitos de água. A maioria (84,0\%) combatia ratos, moscas e baratas e, desses, 82,5\% usavam veneno para extingui-los. Porém, 16,0\% disseram não fazer nada para eliminar os insetos.

\section{PARTICIPAÇÃO COMUNITÁRIA NO PROCESSO DE IMPLE- MENTAÇÃO DO PROSANEAR I}

Em 1988, a Associação dos Moradores do Conjunto Palmeiras deu um prazo de um mês para a Companhia e Água e Esgoto do Ceará (CAGECE) implantar água encanada. Caso isso não acontecesse, os moradores ameaçavam destruir a adutora de água que ia para o bairro Aldeota (classe alta da cidade) e que passava pelo Conjunto. Em um dos grupos focais, os moradores falaram sobre a compreensão do processo: "Foi anunciado na radiadora e o pessoal fez a maior manifestação. Se não colocassem água para todo pessoal dentro do conjunto Palmeiras, nós iamos furar os canos. A gente sabia que todo mundo ia ser inundado, mas eles, na Aldeota, iam sentir a falta d'água porque lá não ia ter água. Então, o governo, devido à pressão, colocou água imediatamente no Conjunto Palmeiras" (GP2). De fato, os moradores já estavam solicitando o serviço há 12 anos. Houve uma série de passeatas, mas só em 1993, a CAGECE se prontificou a resolver a questão.

No Conjunto São Bernardo, a comunidade também se mobilizou. Segundo alguns, o Prosanear I veio devido à luta contínua dos moradores: "Nós 
fizemos muitas caminhadas até o Cambeba para chamar, para pedir, para implorar e para entregar muitos ofícios" (GB2). Mesmo não sendo atendidos, eles insistiam nas reivindicações: "A gente era embargado, voltava para casa, tentava no outro mês, faz̧ia batucada debaixo do prédio deles até eles atenderem a gente" (GB2).

Os projetos foram implantados pela CAGECE, que contratou uma consultoria para realizar, entre outras coisas, um levantamento socioeconômico das comunidades. Para a implantação do projeto, reuniões e visitas nas casas pelos representantes da associação e pelos profissionais da consultoria foram feitas com o objetivo de explicar a proposta do Prosanear I e envolver os moradores na aceitação do projeto.

De acordo com 72\% dos moradores do Conjunto Palmeiras e 76\% do Conjunto São Bernardo houve discussão e explicação sobre a vinda da água e do esgoto, mas para 28\% dos entrevistados Palmeiras e 24\% do São Bernardo não houve nenhuma comunicação. Essa parcela de moradores não envolvida prejudicou a implantação do projeto, pois muitos optaram por não colocar água e esgoto em suas casas, causando problemas para o resto da comunidade, devido aos hábitos não coletivamente coerentes.

Com relação à participação dos moradores na implantação do projeto houve algumas limitações. Para alguns moradores do Conjunto Palmeiras, o processo de informação e esclarecimento do projeto foi insuficiente e, consequentemente, não ocorreu plena participação. "Muitas pessoas não sabiam das reuniões” (GP5). Para outros moradores, as reuniões deveriam ocorrer em vários horários para que todos pudessem ir, pois muitos além de trabalharem fora também tinham que cumprir afazeres domésticos: "Tem muita gente, como eu, que não quer sair de casa de manhã, pois tem tanta coisa para fazer. No meio da reunião, uns tinham que voltar para casa porque tinham problemas. Ai em vez de sair de casa para perder tempo, eles não saíam e faziam igual ao que eu fir. Eu nunca vim" (GP1).

Outro fator que também não foi levado em conta com relação ao esvaziamento das reuniões, de acordo com os moradores, foi a falta de coordenação do processo de discussão, o que dificultou o entendimento entre moradores: "Era muito difícil eu ir para as reuniões porque havia muitas brigas. Eu só não ia mais por causa disso. As brigas eram constantes, a gente não gosta de ver briga e a gente não $i a^{\prime \prime}$ (GB2).

A falta de participação de grande número de pessoas nas reuniões, segundo os entrevistados do Conjunto São Bernardo, acabou desmotivando quem estava participando, já que este procurava mudar seus hábitos e percebia que outros não faziam o mesmo: "Muita gente tem falta de interesse porque a gente marca uma reunião para discutir os problemas do bairro e só vem 10 pessoas. Se fosse para falar da vida alheia, muitos

Novos Cadernos NAEA • v. 16 n. $2 \cdot$ p. 319-339 • dez. 2013 
viriam. A gente tem interesse de resolver os problemas, mas ninguém aparece, ninguém tem interesse. O negócio dessas pessoas é fazer sujeira, mas elas não ajudam a gente a se comunicar e a resolver os problemas. Muita gente não tem interesse" (GB1). Em vários momentos ficou perceptível o descontentamento com a escassez nas participações: "Os moradores devem se interessar para saber qual o problema que está havendo. Todos deveriam se reunir para saber uma maneira mais fácil de resolver o problema. A nossa comunidade não se fala e não discute nada. A reunião não existe" (GB1).

A falta de interesse, conforme alguns moradores do Conjunto Palmeiras, prejudica a participação comunitária: "Todo mundo quer mudança, mas ninguém quer participar. Preferem ficar em casa e ver novela” (GP1). Alguns sabem que a falta de participação legitima posições contrárias às suas, mas mesmo assim nada fazem sobre isso. "A pessoa se acomoda e acha que aquilo ali não vai resolver nada. Ela acredita que é melhor deixar para lá e acaba botando na cabeça que a reunião não vai resolver nada. Os que vão tomam decisão pela maioria, ou seja, uma minoria aprova. As pessoas que estavam na reunião escolhem do jeito que elas acham melhor" (GP5).

Afazeres domésticos, trabalho, desconhecimento das reuniões e brigas foram usados como justificativa para não participar. Os entrevistados disseram que as visitas dos representantes do projeto deveriam ter sido mais frequentes e que não houve valorização da fiscalização comunitária na execução das obras, o que propiciou alguns descontentamentos: "Eu perguntei ao pedreiro se ele não estava achando os canos muito finos. Ele disse que estava cumprindo ordens e que foram aqueles os canos que deram para ele colocar" (GP4). A mesma comunidade avisou sobre a ineficiência de algumas construções e instalações, que posteriormente foram constatadas: "A gente quer que a Cagece corrija os defeitos que ficaram na instalação da rede de esgoto. Tem várias pessoas que estão reclamando que o declive ficou muito pouco, então a Cagece deve fazer vistorias para ver se precisa recuperar alguns trechos. Ela deve acabar de vez. com os problemas de entupimento nas casas que entopem sempre" (GP2).

Outra ausência de participação da comunidade no processo decisório do Prosanear I aconteceu quando os representantes do projeto não levaram em conta a escolha dos moradores no que diz respeito à localização da passagem dos canos de esgoto. A maioria queria a tubulação pela frente da casa e não pelos quintais, como foi realizado.

A participação é uma das mais importantes variáveis do Prosanear I. Segundo o Banco Mundial, os moradores deveriam participar do planejamento, construção e manutenção do sistema. Quando o Banco defende o uso de tecnologias de baixo custo, ele afirma que cabe aos moradores, dentro do sistema condominial, fazer uma "opção tecnológica" entre três alternativas: tubulação no quintal, na frente da casa e na calçada. Como opção significa preferência 
e livre escolha, supõe-se que cada comunidade tenha liberdade suficiente para determinar o que prefere e o que lhe é indiferente. Vários documentos, todavia, comprovam que a participação comunitária defendida pelo Banco foi limitada pelos órgãos executores a alguns aspectos previamente determinados.

A participação proclamada pelo Banco Mundial, neste caso, não aconteceu, pois a decisão sobre a tecnologia a ser usada já estava antecipadamente tomada. Dessa forma, definiu-se a localização no quintal pelos custos serem menores. Assim, os moradores deveriam apenas estar "convencidos" da melhor opção. Tudo isso gerou um grande descontentamento por parte dos moradores e, consequentemente, falta de participação.

A participação comunitária é um importante canal de informação, pois um público mal informado pode sumariamente rejeitar uma proposta. Nos dois casos analisados não houve participação popular efetiva na fase de elaboração dos projetos. O público, na maioria das vezes, tem um documento já preparado e, quando muito, é perguntado se aceita ou rejeita tal proposta.

Embora sejam reconhecidos alguns impactos positivos da água e do esgoto, alguns problemas e distorções foram constatados: "O Prosanear deu certo para uns e não deu certo para outros" (GP4). Assim, 34,0\% dos entrevistados no Conjunto Palmeiras afirmaram que esperavam coisas que não foram realizadas com a vinda do Prosanear I. No Conjunto São Bernardo, esse percentual subiu para 41,5\%. Os moradores do Palmeiras mencionaram como principais pontos não atendidos: discussão/reunião com a comunidade, tubulação de esgoto na frente, fim do esgoto correndo na rua e assistência técnica disponível. Já os domiciliados no Conjunto São Bernardo indicaram a falta de discussão/reunião com a comunidade, tarifas mais baixas e fechamento do canal.

Vários problemas foram levantados com relação ao serviço de fornecimento de água pela comunidade do Conjunto Palmeiras. A inconstância no valor das tarifas e o elevado preço das mesmas geraram reclamações. No primeiro caso, os moradores foram impossibilitados de planejar as suas despesas familiares. No segundo, eles se sentiram impedidos de usufruir o serviço como gostariam, diminuindo inclusive a higiene pessoal, pois sabiam da relação direta existente entre preço e consumo. Afirmaram que "Não se pode tomar muito banho, só um banho por dia. Ninguém pode tomar dois banhos que gasta muita água. Hoje é R \$15,00 e quando for no mês que vem vai ser $\mathrm{R} \$ 20,00$. Ai vai aumentado, vai aumentando e pouco mais a gente está pagando $\mathrm{R} \$ 30,00$ ou $\mathrm{R} \$ 40,00$ só de água” (GP1).

Algumas pessoas, contudo, afirmaram que consomem sempre a mesma quantidade de água, mas suas contas vêm aumentando constantemente e elas não sabiam o motivo. "Era só para vir a taxa que a gente espera. A água vem um absurdo. Se

Novos Cadernos NAEA • v. 16 n. $2 \cdot$ p. 319-339 • dez. 2013 
em um mês eu pago $R \$ 40,00$, no outro mês vem $R \$ 28,00$ e no outro mês já vem $R \$ 38,00$, porquê? Baixa um mês e sobe em outro para quem faz aquela base do jeito que vem em todo canto" (GP1). Ou ainda quando afirmavam: "Como é que a gente não gasta tanta água desse jeito e veio esse preço aí?” (GP1). Os moradores buscavam explicações para os aumentos crescentes dos preços nas formas de se calcular as tarifas: "Parece que eles inventaram o negócio dessa máquina de calcular. Eles chegam, batem ali naquele número e entregam o papel. Foi pior. Dobrou o valor das contas" (GP1). O defeito no medidor de consumo é frequentemente mencionado: "Eu ouvi várias denúncias contra a Cagece porque tem medidor que não está funcionando bem, que está acusando mais água” (GP2). O vazamento de água completava o conjunto das prováveis causas apontadas para o aumento de tarifas: "Tem dois vazamentos no cano do vizinho da frente. Ele perde tanta água e tanta água é destruida na nossa frente. Tanta gente com sede e nós aqui destruindo água" (GP2).

A tarifa do esgoto é um caso a parte, pois seu valor vem agregado ao consumo da água, ou seja, se alguém consumir $\mathrm{R} \$ 20,00$ de água, ele vai pagar $55 \%$ desse valor pelo esgoto. O percentual do esgoto defendido inicialmente era de $60 \%$ do valor da água, após negociações com os representantes comunitários a porcentagem caiu para 55\%. Contudo, os beneficiários não entendiam essa forma de cálculo/cobrança e nem concordavam em pagar pelo esgoto: "Eu tive dúvidas porque elas falaram que a gente tinha que pagar aquela taxa junto com a água. A gente ganha 1 salário e 1 salário não dá para a gente nem sobreviver. A maioria não podia pagar esgoto" (GP3).

A cobrança de tarifas pelas ligações domiciliares, pelo uso da água e pela coleta de esgoto é defendida pelo Banco Mundial como uma forma de garantir o comprometimento da população com o serviço. Sob esta ótica, o serviço não poderia ser gratuito, porque não despertaria o zelo pelo sistema. Esta é apenas uma forma de ver a questão e nem sempre existe uma relação direta entre a cobrança de tarifas e o comprometimento dos usuários. Pode acontecer de o usuário se achar no direito de destruir porque paga, como aconteceu em alguns casos de entupimento nos locais analisados. Não raro a população quebrava os canos da rua como demonstração de protesto. De fato, o envolvimento só se dá mediante a participação e a conscientização da comunidade. O que leva as pessoas a se comprometerem é o esclarecimento dos objetivos e das informações corretas, a educação continuada de todos os moradores da casa - pois nem sempre quem vai a uma reunião socializa o conhecimento para todos da família - a participação e o acompanhamento.

$\mathrm{Na}$ verdade, o poder público não dispõe de verbas suficientes para implementar os programas e se utiliza dos financiamentos externos para suprir, 
de forma deficiente, os excedentes de demanda por serviços. Assim, tenta transferir para a comunidade a recomposição dos custos, por meio da cobrança de tarifas à população. $\mathrm{O}$ aumento das tarifas públicas, além do mais, costuma ser um instrumento de política fiscal do governo. A população envolvida, de fato, não consegue visualizar como uma decisão política afeta diretamente seus bolsos.

De acordo com 64,0\% dos moradores do Conjunto Palmeiras e 61,0\% do São Bernardo, a água e o esgoto vão apresentar problemas no futuro. A maioria dos moradores tanto da primeira comunidade (62,5\%) quanto da segunda $(61,0 \%)$, apontou o entupimento do esgoto como a principal dificuldade que poderá surgir no sistema implantado. As dificuldades vividas pelos moradores com relação ao entupimento podem ser visualizadas nos seguintes trechos: "No inverno, a minha cozinha, que é bem grande, ficou alagada. Chovia e subia água pelo ralo do banheiro" (GP2). Ou ainda: "Quando o esgoto enche, o rapaz, vem, desentope, mas depois entope de novo. Eu vivo a minha vida assim: entope e desentope" (GB1). E mais: "Eu preferia a minha fossa do que esse esgoto. Antigamente, a minha casa não amanhecia cheia d'água" (GB1).

O entupimento do esgoto tem duas explicações básicas: a técnica e os materiais utilizados no projeto e a falta de educação sanitária dos moradores. No primeiro caso as críticas se assentam sobremaneira no local escolhido para passar a tubulação do esgoto, a falta de atenção com relação ao nível das casas e o calibre dos canos. O sistema condominial implantado no fundo do lote liga todas as casas pelos seus quintais. A população, contudo, reclamava bastante dessa localização, pois: "Se fosse no meio da rua, como era para vir, o nosso quintal era limpo e não tinha negócio d'água nenhum" (GP1). Ou ainda: "Enquanto eles não tirarem o esgoto dos quintais das casas, o problema não vai ser resolvido. Se eles tivessem feito no meio da rua, nós não teríamos esses problemas. Eu acho que eles deveriam procurar uma maneira mais fácil de acabar com o esgotamento dos quintais das casas. Eles deviam fazer o esgoto no meio da rua. Eu garanto que iria melhorar 100\% a vida da população" (GB1).

A outra causa principal de entupimento reside na carência educacional da comunidade. Uma mudança de hábitos deveria pressupor um processo educacional, já que não se modificam instantaneamente atitudes arraigadas. $\mathrm{O}$ tempo, inimigo das planilhas de custos dos projetos, deveria passar a ser visto como aliado. As mudanças de hábitos demandam tempo, disponibilidade para aprender, instrutores e acompanhamento dos aprendizes. Um aprendizado evitaria um incidente como: "Outro entupimento que houve foi uma carne moída que passou do tempo de vender. Mandaram os meninos jogarem fora e eles botaram dentro da caixa de esgoto. Eram dois sacos de carne moída de dois quilos cada. Isso deu um entupimento grande. As casas de vários vizinhos foram invadidas pelo banheiro" (GP2). Há o reconhecimento da falta de educação sanitária 
por parte das comunidades e há também propostas de soluções para os problemas enfrentados, todavia a mudança de hábitos não acontece em curto prazo e sem a ampla participação de todos os atores envolvidos. "Por que as mulheres não ajuntam seu lixo? Ao invés de jogar dentro daquele esgoto, que é esgoto público e é da Prefeitura. Elas deviam pôr em sacos e esperar o carro passar" (GP2).

De acordo com dados do survey, 82,5\% dos entrevistados no Conjunto Palmeiras afirmaram que tiveram ensinamentos sobre conservação/manutenção do sistema de água e de esgoto. No Conjunto São Bernardo, esse percentual subiu para 93,5\%. Algumas pessoas enfatizaram como foram os treinamentos: "Eles ensinaram mesmo foi só evitar a comida de entrar no esgoto" (GP1). "Eles disseram que não deixasse cair sabonete, pedaço de sabão quando a pessoa estivesse tomando banho porque prejudicava muito o ralo. Eles explicaram tudo direito. Não era para cair nada no ralo" (GP2). "Eles disseram que não podia botar papel higiênico no aparelho. A gente tinha que ter zelo porque era melhor para a gente e para eles" (GP3).

Outros, contudo, disseram que nada foi ensinado: "Eu não fui treinada e nem fui ensinada, mas eu tenho o máximo de cuidado" (GB1). "Quando eles vieram aqui, não ensinaram nada" (GB1). Se há diferenças nas atitudes das próprias pessoas que participaram dos treinamentos, certamente haverá ainda mais distorções entre aqueles que ficaram isolados do processo de aprendizagem. Uma das questões levantadas é que nem todos tiveram educação sanitária devido ao número pequeno de instrutores disponíveis: "Existiam apenas três pessoas e teve muito canto no bairro que eles não puderam visitar. Eles não cobriram o bairro todo" (GP3).

A dificuldade do serviço de manutenção é outro ponto problemático, pois como havia constantes entupimentos, tornavam-se necessárias pessoas disponíveis para atendimento imediato. Grande parte das chamadas se concentrava nos finais de semana já que o número de usuários cresceu bastante: "Quando o saneamento estoura no domingo, a gente pede socorro, exige rapidez.por causa da emergência e é atendido, mas o atendimento demora muito. A gente se ofende muito com a demora" (GP5). A demanda pelo serviço de manutenção era grande e o número de funcionários para desempenhar tal função insuficiente. "O rapaz, vem, faz o trabalho direito e não resolve. Ele chama o caminhão e passa de três a quatro dias para a equipe vir. Eu vi o rapaz. ligar e eles disseram que não vinham hoje, que só vinham amanhã" (GB1).

Enquanto esperava, a população tentava resolver a situação de maneira imediata e buscava novas alternativas: "Eu lavo com querosene, pois é tudo dentro de casa" (GP2). "Eu sempre meto um cano lá para desentupir e eu sempre aviso para ferver uma chaleira d'água e jogar dentro. O que eu vou usar agora é ácido muriático porque ele é muito bom para derreter a gordura" (GB2). "A gente ferve água e joga dentro do cano para tirar a gordura. O sebo se dissolve" (GP4). 
$\mathrm{Na}$ ânsia de chegar a um consenso, alguns membros da equipe de um projeto escutavam certas reivindicações. Assim, várias discussões aparentavam instituir regras que não foram estabelecidas por ninguém. As promessas, nesses casos, podiam surgir em dois momentos: 1) alguém que deseja a aprovação coletiva se compromete a tentar resolver as insatisfações pendentes e, 2) alguém não usa de má fé, mas igualmente se compromete a levar em conta as reivindicações. As duas situações podem gerar grupos insatisfeitos. Quando o discurso se distingue da realidade, as pessoas se decepcionam e passam a não ter comprometimento. A seguir destaques discursivos que evidenciam o que está sendo dito: "O negócio foi muito diferente do que eles explicaram, foi muito diferente. Falaram de um jeito e veio de outro" (GP1). "A moça chegou e disse que eles iam quebrar e que iam deixar do mesmo jeito. Eles não deixaram nada do mesmo jeito. Eles deixaram várias coisas quebradas. Parecia que tinha passado um ladrão" (GP3). "Os homens do projeto fizeram reuniōes, prometeram várias coisas e não fizeram do jeito que eles disseram. Muita gente não concordou com o esgoto por causa dessas mentiras" (GP5). "Eles disseram que a gente não ia ter problema e que o esgoto ia ser uma coisa boa. O esgoto não funcionou como eles prometeram" (GB1). "Eles disseram: 'O saneamento vai ser feito', 'A coisa vai melhorar e vai ficar boa para vocês', 'Não vai ter mais catinga' e Não vai ter mais nada.' Ninguém viu nada disso” (GB1).

A imposição da equipe é mencionada pelos moradores como um exemplo de que eles não eram ouvidos e, portanto, suas ideias não eram levadas em consideração. Eles aceitaram porque nada melhor seria oferecido: "É uma coisa botada pelo governo. Tem que ser assim, tem que ser" (GP1). "Eles faziam o que queriam. Eles achavam que o Conjunto era de gente pobre e faziam o que queriam. As pessoas ficam caladas e o povo não falava nada. A gente teve que aceitar. A gente aceitou para ver se melhorava a situação" (GP1). "O Prosanear só deu certo no gabinete de quem fez ele" (GP4).

\section{IMPACTOS SOCIAIS E ALGUMAS CONSIDERAÇÕES FINAIS}

Os moradores dos Conjuntos Palmeiras e São Bernardo vivenciaram a implementação do Prosanear I e apresentaram sugestões de solução para os problemas enfrentados, indicando a centralidade da participação. As sugestões apresentadas enfatizavam a importância da mobilização: "A gente deve procurar uma solução. A gente deve anotar quais são as quadras e chamar a CAGECE. Eles vão ter que mudar os canos de dimensão para evitar esses entupimentos porque a gente tem que ficar metendo o ferro em quase todas as ruas para concertar os erros que tinha. Se já era um erro quando a pessoa fez, então ela fezo projeto errado. Ela tem que procurar ajeitar. Ela não pode deixar esses problemas ficarem toda vida. A gente pode até deixar o número da casa anotado

Novos Cadernos NAEA • v. 16 n. $2 \cdot$ p. 319-339 • dez. 2013 
na Associação. Ela pode entrar em contato com a CAGECE e ver o que a CAGECE fa\%: A CAGECE é responsável pelo projeto, então não custa a gente ver isso” (GP1).

Enfatizavam ainda que o esgoto devia ser obrigatório para todos, conforme pode ser constatado nas afirmações que se seguem: "A mesma equipe, que no início andava fazendo visitas, deveria fazer visitas novamente. Uma parte das pessoas está vendo o beneficio e deve aceitar agora" (GP3). "O esgoto era para ser obrigatório se fosse uma coisa bem feita, mas você não deve pagar por uma coisa mal feita" (GB1). E destacaram ainda que a educação sanitária continuada não podia ser desprezada: "Precisa-se de educação sanitária nas pessoas para evitar que ninguém coloque nada nos canos" (GP2).

Vários problemas de concepção do Prosanear I não foram resolvidos e por isso apresentaram efeitos perversos. As críticas, desilusões e a participação limitada de parte dos moradores causaram muitas situações desagradáveis para a própria comunidade. Percebe-se, de fato, que essas questões poderiam ter sido observadas no Conjunto Palmeiras e foram recriadas no Conjunto São Bernardo. A análise pontual de alguns impactos sociais confirma essa constatação, bem como comprova a essencialidade de metodologias capazes de corrigir o rumo dos projetos e das políticas públicas.

A análise dos questionários permitiu observar que 94,0\% dos moradores do Palmeiras e 89,0\% do São Bernardo reconheceram que o Prosanear I teve impactos positivos na vida da comunidade, especialmente quanto à habitação, saúde e higiene. Esses resultados são corroborados pelos depoimentos nos grupos focais. $76 \%$ dos entrevistados do Conjunto Palmeiras disseram que houve mudanças satisfatórias em habitação, 82,5\% em saúde e em higiene. No Conjunto São Bernardo, essas porcentagens foram bem parecidas, pois $82,5 \%$ responderam que houve modificações em habitação, 80,5\% em saúde e 82,5\% em higiene. Portanto, pode-se concluir que houve impactos positivos nesses três setores nos dois conjuntos.

No que diz respeito à água encanada, os moradores sustentaram que a sua disponibilidade facilitou o desempenho das tarefas caseiras e contribuiu para melhores condições de higiene do ambiente doméstico. De acordo com os moradores: "Eu lavava roupa assim: pegava uma bacia, rebolava a água no quintal e ficava tudo molhado, tudo cheio d'água. Eu achei bom porque hoje tem a pia, en lavo na pia e a água escorre por aquele cano. Graças a Deus, não tem mais molhadeira no quintal da minha casa" (GP1). "Dá para varrer a casa da gente e não tem mais sujeira. Antigamente, aqui na Palmeiras, tinha muita sujeira, mas agora não tem mais, ou melhor, tem pouca" (GP2).

Ao possibilitar maior limpeza do espaço de moradia, a disponibilidade de água encanada provocou um impacto positivo sobre a saúde das crianças: "A água realizou nossa esperança e acabou com aquelas águas velhas. As crianças pararam mais de 
adoecer. As crianças ficavam no meio daquelas águas velhas e sujas. Agora, tudo está limpinho" (GP3). A saúde da família e da comunidade também apresentou mudanças positivas, pois $77 \%$ dos entrevistados no Conjunto Palmeiras afirmaram que a saúde da sua família estava melhor depois da água e do esgoto e $82 \%$ afirmaram que a saúde dos vizinhos também melhorou. No caso do Conjunto São Bernardo, $80,5 \%$ disseram que tanto a saúde dos seus familiares como de seus vizinhos estava melhor.

Com relação ao esgoto também foram mencionados alguns impactos positivos. O escoamento pela tubulação da água usada em casa e da água da chuva, por exemplo, passou a evitar o acúmulo de lama e, portanto, o aparecimento de mosquitos. Essa melhoria é um fator importante na redução das doenças e no melhoramento da vida ambiental do bairro. Os moradores afirmaram que "A gente não tinha um canto para colocar a água do banho, a água da roupa e qualquer água que fosse. Era tudo no meio da rua e quando não era no meio da rua era no quintal. Se a gente jogasse água um pouco, o vizinho achava ruim. Agora fica tudo num canto só” (GP1). "A minha casa era num lugar muito baixo. A água invadia e agora, principalmente quando chove, não entra mais água para dentro de casa porque tem o esgoto e vai para o esgoto" (GP1). "Antes do Sanear era uma lama medonha. Ele evitou acumular mais doenças. Hoje ainda tem muito dengue, cólera, mas é menos" (GP2). "O esgoto foi bom porque diminuiu as muriçocas. Aquele mato, aquele mosquito e aquela sujeira melhoraram muito" (GP4).

Um dos pontos polêmicos do Prosanear I, como mencionado antes, foi a localização das tubulações de esgoto. $O$ fato das tubulações terem sido implantadas na frente das casas, ou nos seus quintais, passou a ser associado com o maior problema do projeto: o entupimento. A notícia de que outros bairros tinham água e esgoto e, portanto, viviam entupidos amedrontava as pessoas, que assim se manifestavam: "Outros bairros de Fortaleza que já tinham feito o projeto, como o Genibaú, o Lua Fumaça, o Couto Fernandes e o Dias Macedo, tiveram problemas. Algumas pessoas tinham conbecimento que o projeto nesses bairros não tinha funcionado" (GP5). "O Genibáu entupiu quase todo o bairro. Um novo encanamento teve que ser feito. Os tipos dos canos foram modificados porque eles não tinham condições de passar o volume dos detritos." (GP5).

A falta de dados concretos dos responsáveis pelo projeto mostrando que aquela situação não aconteceria no Conjunto Palmeiras formou uma atitude contrária de várias pessoas da comunidade. Essa atitude foi uma das causas principais da falta de envolvimento público. Então, tem-se também impactos negativos: 1) a formação de atitude contrária ao projeto e, 2) a falta de envolvimento do público, que, por outro lado, gerou a não participação.

Quando as pessoas de uma comunidade ouvem pela primeira vez falar de um projeto, elas costumam ter as mais diversas reações: contentamento, no 
caso das reivindicações atendidas; surpresa, nas decisões públicas não esperadas e descontentamento, nas imposições de políticas. Alguns procurarão mais informações, outros, se negarão a participar. Um projeto, contudo, para ser bem sucedido deve não apenas ter o apoio dos interessados, mas também arrebanhar os que sejam contrários a ele. Assim, uma formação de atitude positiva é de suma importância na fase inicial de qualquer política, pois a crença comum de que haverá prejuízos minimizará a percepção dos futuros benefícios.

A situação das casas localizadas nas partes mais baixas dos Conjuntos, no caso de entupimento, é mais grave, pois a água desce e lá fica empoçada. Para muitos, o desconhecimento da topografia da área impossibilitou que se fizessem os aterros indispensáveis para que o sistema funcionasse de maneira eficaz. Os moradores afirmaram que "O pessoal que mora em cima não se prejudica, mas os que moram embaixo se prejudicam" (GB1). Isso causou um conflito entre dois grupos de residentes e, portanto, gerou um impacto social negativo: Os moradores da parte alta, bastante satisfeitos, e os da parte baixa, desgostosos. Enquanto os primeiros procuravam enfatizar o quanto era bom ter água e esgoto, embora reconhecendo que os da parte baixa tinham problemas, os segundos eram gratos pela água e queriam se livrar dos problemas do esgoto. Essa diferença de qualidade do serviço dificultou uma mobilização desses dois grupos em torno de uma meta comum.

A tecnologia de baixo custo, de acordo com o Banco Mundial, além de ter um orçamento mais acessível tem outra vantagem: Como os quintais são ligados, quando entope em uma casa, a residência vizinha possivelmente entupirá. Para o Banco, tal fato estimularia a união e a cooperação entre os moradores de cada rua. Assim, os vizinhos ligados por um objetivo comum não causariam problemas uns aos outros e acabariam fazendo funcionar o sistema. Dessa forma, cada um deveria fazer a sua parte e evitar entupir. Caso alguém não cuidasse da manutenção do sistema e causasse um entupimento, ele estaria prejudicando toda a rua e, consequentemente, se prejudicando. Dessa forma, para o Banco Mundial, se um perdesse, todos perderiam e o interesse próprio deveria causar a união e produzir a cooperação.

Nessa suposição, o Banco não levou em conta as diferenças pessoais e as dificuldades naturais das relações humanas. $\mathrm{Na}$ prática, observou-se que os constantes entupimentos conduziram a situações de discórdia e não de cooperação. As entrevistas demonstraram que a esperada cooperação entre vizinhos não ocorreu em várias situações: "Eu tenho uma viz̨inha que, se ela perdeu o carro do lixo, ela pega os dois saquinhos do lixo dela e sai botando na porta dos outros" (GP2). "A vizinha cria muitos cachorros. Ela lava, bota toda a água para fora e fica a água 
toda empoçada em frente da minha casa. Ela não queria aceitar o esgoto e depois aceitou, mas não fez o cano para lavar roupa e a água suja desce toda para a rua" (GP3). "Essas pessoas da comunidade têm que entender que elas estão fazendo mal não só a elas, mas a todo mundo. Se você tem saneamento, água, esgoto e bota dentro todo tipo de sujeira, então isso vai prejudicar todo mundo um dia” (GB1).

O Banco Mundial também defende a necessidade de conjugar projetos de água e de esgoto, pois caso só o primeiro seja realizado, as pessoas, por falta de escoamento, irão jogar água nas ruas. No Conjunto Palmeiras, contudo, uns aceitaram o saneamento e outros não, ou seja, o saneamento não foi obrigatório para todos. Dessa forma, houve residências que só quiseram o projeto da água prejudicando os demais moradores: "Se todo mundo tivesse aceitado, não haveria mais problema de água na rua e estaria tudo bem. O esgoto é igual a energia, todo mundo tem que fazer. Se todo mundo tivesse pensado duas vezes, ninguém teria rejeitado o projeto. Quem rejeitou complica os outros. A sujeira deles desce para frente da casa dos outros" (GP3). Um dos grandes impactos negativos para o meio ambiente foi a continuidade de águas servidas escorrendo pelas ruas.

O Prosanear I no Conjunto Palmeiras teve uma série de impactos positivos como a melhoria da higiene pessoal, das condições de saúde e da qualidade de vida; e negativos como a formação de atitudes contrárias ao projeto, a falta de envolvimento do público, a elevação no preço das tarifas, o conflito entre residentes e a piora de algumas condições ambientais. Caso os tomadores de decisão do Prosanear I no Conjunto São Bernardo tivessem feito uma avaliação do impacto social e escolhido como modelo comparativo o Conjunto Palmeiras, teriam percebido que várias consequências negativas poderiam ter sido evitadas. Vale destacar que todos os impactos negativos observados no Conjunto Palmeiras foram também percebidos no São Bernardo. A avaliação de impacto social como instrumento de formulação e decisão diminuiria os custos do projeto, devido as menores interrupções do mesmo, e também evitaria reações adversas.

\section{REFERÊNCIAS}

CLAIRMONT, F. F. L'économie mondiale est-elle sur condamnée aux crises perpétuelles? Le Monde Diplomatique, Paris, p. 12-13, dez. 1994.

LESLIE, W. J. The World Bank and structural transformation in developing countries: the case of Zaire. Colorado: Lynne Rienner Publishers, 1987.

LIMA, M. R. S. Teses equivocadas sobre a ordem mundial pós-Guerra Fria. Dados - Revista de Ciências Sociais, Rio de Janeiro, v. 39, n. 3, p. 393-421, 1996. 
MASON, E. S.; ASHER, R. E. The World Bank since Bretton Woods. Washington, DC: The Brokings Institution, 1973.

ROSANVALLON, P. La nouvelle question sociale. Paris: Editions du Seuil, 1995.

SANTOS, M. M.; PAULA, L.F. R.. Análise da política de saneamento no Brasil. In: CEPAL. A política social em tempo de crise: articulação institucional e descentralização. Brasília: MPAS/CEPAL, 1989. p. 281-354. v. 3.

SMOLKA, M. O. Velhas novidades na agenda do Banco Mundial para a política urbana nos anos 90. In: GONÇALVES, M. F. (Org.). O novo Brasil urbano: impasses, dilemas, perspectivas. Porto Alegre: Mercado Aberto, 1995. p. 307-330.

SOTERO, P. Mundo perde guerra contra miséria, alerta BIRD. Estado de São Paulo, São Paulo, 16 set. 1999. Caderno Geral, p. A13.

WORLD BANK. World Bank Participation Sourcebook. Environment Departament Papers. June, 1995.

ZALUAR, A. Exclusão e Políticas Públicas: dilemas teóricos e alternativas políticas. Revista Brasileira de Ciências Sociais, São Paulo, v. 12, n. 35. Fev. 1997. 
Novos Cadernos NAEA • v. 16 n. 2 • p. 319-339 • dez. 2013 